\title{
In vitro Screening of Chilli (Capsicum anum L.) Genotypes against the Colletotrichum capsici causing Anthracnose of Chilli
}

\author{
Manoj Kumar Prajapati*, Dr. Shilpi Rawat, Deepak Prakash, \\ Kripa Shankar and Jitesh Kumar
}
Department of Plant Pathology, College of Agriculture, G. B. Pant University of Agriculture and Technology, Pantnagar, Udham Singh Nagar, Uttarakhand-263145, India

*Corresponding author

\begin{abstract}
A B S T R A C T
An investigation was carried out at experimental block for chilli crops, Vegetable Research Centre, Pantnagar with ten promising genotype of chilli to assess or screen resistance to anthracnose (Colletotrichum capsici) under in lab condition. The experiment was conducted during rabi season of 2018 - 2019 following Completely randomized block design with three replication. Results revealed that among the 10 genotypes tested under in lab condition for screening against $C$. capsici, six genotypes of chilli including LUCKNOW-1, CHIHYB-11, CHIVAR -7, CHIHYB-8, CHIHYB-13 and Pant C-1 were shown to be moderately resistant having mean lesion length of $1.94-1.02 \mathrm{~cm}$ with PDI of 5.54- 13.49 whereas the genotypes CHIHYB-12 and CHIVAR -2 showed absolutely susceptible reaction having mean lesion length of 2.61 and $2.13 \mathrm{~cm}$ with PDI of 27.72 and 31.81 respectively. The genotypes CHIHYB-9 and NISHANT exhibited highly susceptible reaction having mean lesion length of 3.80 and $3.95 \mathrm{~cm}$ with PDI of 51.05 and 58.27 per cent respectively. Pant C-1 variety showed least mean lesion length $(1.02 \mathrm{~cm})$ with minimum PDI $(5.54 \%)$ and found to be much better than other varieties. None of the varieties found resistant among these.The genotypes with moderately resistance reaction could be considered as a promising breeding material for development of high yielding anthracnose resistant chilli variety.
\end{abstract}

\section{Introduction}

Chilli (Capsicum annum L.) is one of the most important constituent of the cuisines of tropical and subtropical countries and the fourth major crop cultivated globally. Nutrition wise it is rich source of Vit A and C content; high iron, potassium, and magnesium content with the ability to boost the immune system and lower the cholesterol levels (Grubben and Mohamed El, 2004).India is a leading producer, consumer and exporter of dried chilli in the world. In India, total cultivated area and production have been estimated 309 Mha and 3592 MT respectively (NHB 2017-18). In Uttarakhand, the total area 
and production have been estimated 2762.08 ha and 9158.16 Metric tons respectively (Anonymous, 2018).

Though there is scope for enhancing the production of chilli in the state, biotic factors like diseases hamper their successful cultivation. The major diseases affecting the crop include anthracnose and fruit rot, bacterial wilt, chilli mosaic, mottle and leaf curl are the most serious destructive diseases of chilli (Issac, 1992 and Anand et al., 2010). Anthracnose of chilli caused by Colletotrichum capsici (Syd.) Butler and Bisby has been considered as a most notorious pathogens worldwide causing economically important disease anthracnose (die-back, ripe fruit rot and leaf spot) in a wide range of hosts including cereals, legumes, vegetables, perennial crops and tree fruits (Bailey and Jeger, 1992; Dean et al., 2012 and Freeman et al., 1998). The disease intensity in Uttarakhand has been found to be increasing due to changing environmental conditions and has become a concern for the farmers. Since the screening of chilli genotypes under lab condition which helps in identification of resistance sources in genotypes in a short period of a time and it can be selected and used in breeding programmes to develop resistant varieties is the most efficient, non-hazardous, environmentally safe and economical way to manage plant diseases.

\section{Materials and Methods}

Ten different genotypes of chilli varieties (Table1 and Plate1) normally grown in Vegetable research Centre (VRC) Pantnagar were screened out under laboratory condition against the test pathogen by Pin Prick Method (PPM). Fresh chilli fruits collected from VRC were surface sterilized with sodium hypochlorite $(1 \%)$ for 30 seconds, washed thrice with sterilized distilled water and air dried by placing on sterilized blotter paper and subsequently inoculated by PPM with spore suspension $\left(1 \times 10^{6}\right.$ spores $\left./ \mathrm{ml}\right)$ of fungus under aseptic condition. Spores concentrations were adjusted by haemocytometer. Three fruits per treatment were taken for inoculation and three replication were maintained. The inoculated fruits were placed in moist chamber and incubated at $28 \pm 22^{\circ} \mathrm{C}$. The disease development was recorded by measuring lesion length of the diseased portion and disease severity on $2^{\text {nd }}, 4^{\text {th }}, 6^{\text {th }}$ and $8^{\text {th }}$ days after inoculation (DAI) and disease reaction of each genotype i.e. resistance or susceptibility were assigned based on the visible expression of disease development. Individual selected fruits were graded as per the rating scale of 0 to 5 given by (Jeyalakshmi and Seetharaman, 1998) and disease severity on fruits were calculated. Infection types were characterized as $0=$ no infection (Immune); 1 (Resistant) = up to 5\%, 2 (Moderately Resistant) $=2-10 \%, 3$ (Moderately Resistance) $=10-25 \%, 4$ (Susceptible) $=25-50 \%, 5$ (Highly Susceptible) $=>50$ per cent fruits area infected and disease reaction of each genotype was categorized on the basis of rating scale given by Singh et al., (1993).

Percentage disease index $(\mathrm{PDI})=$

(Sum of individual rating $\mathrm{x}$ 100) / (Total number of fruits observed $\times$ Maximum disease grade)

\section{Results and Discussion}

Pin Prick Method (PPM) was used to inoculate ripe fruits of each variety of chilli and observations were recorded on 2, 4, 6 and 8 DAI and mean lesion length was recorded. The data presented in (Table2 and Plate1) revealed that among these 10 varieties, six varieties of chilli viz., LUCKNOW-1, 
CHIHYB-11, CHIHYB-8, CHIHYB-13, length of $1.25,1.28,1.32,1.43$ and $1.94 \mathrm{~cm}$. CHIVAR -7, and Pant C-1 exhibited were exhibited by LUCKNOW-1, CHIHYBmoderately resistant reaction. Among the different varieties minimum mean lesion length of $1.02 \mathrm{~cm}$ and PDI of 5.54 was observed in variety Pant C-1 showing moderately resistant reaction. Mean lesion 13, CHIVAR -7, CHIHYB-11 and CHIHYB8 with disease severity of 7.13-13.49 respectively exhibiting moderately resistant reaction.

Table.1 List of ten chilli varieties used for screening against $C$. capsici

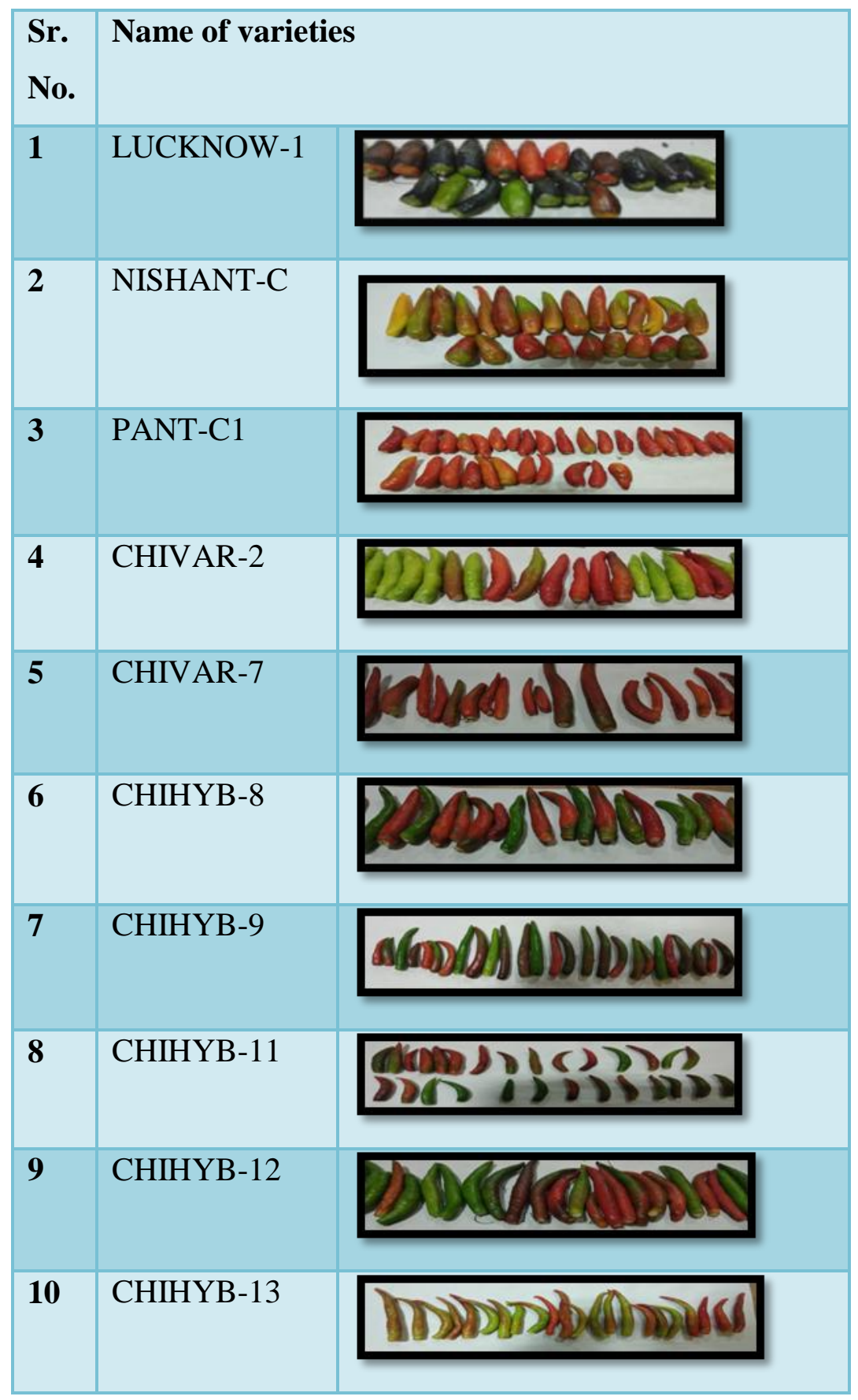


Table.2 In vitro screening of different chilli varieties against Colletotrichum capsici

\begin{tabular}{|c|c|c|c|c|}
\hline $\begin{array}{c}\text { S.N } \\
\text { o. }\end{array}$ & Variety & $\begin{array}{l}\text { Mean lesion } \\
\text { length }(\mathrm{cm}) *\end{array}$ & $\begin{array}{l}\text { Per cent fruit area } \\
\text { covered }(\%)\end{array}$ & Reaction type \\
\hline 1 & CHIHYB-8 & 1.94 & 13.49 & Moderate resistant \\
\hline 2 & CHIHYB-9 & 3.80 & 51.05 & Highly susceptible \\
\hline 3 & CHIHYB-11 & 1.43 & 9.62 & Moderate resistant \\
\hline 4 & CHIHYB-12 & 2.61 & 31.81 & Susceptible \\
\hline 5 & CHIHYB-13 & 1.28 & 7.85 & Moderate resistant \\
\hline 6 & CHIVAR -2 & 2.13 & 27.72 & Susceptible \\
\hline 7 & CHIVAR -7 & 1.32 & 8.02 & Moderate resistant \\
\hline 8 & LUCKNOW & 1.25 & 7.13 & Moderate resistant \\
\hline 9 & Pant C-1 & 1.02 & 5.54 & Moderate resistant \\
\hline 10 & NISHANT & 3.95 & 58.27 & Highly susceptible \\
\hline \multicolumn{2}{|c|}{ SEm \pm} & 0.04 & 0.40 & \\
\hline \multicolumn{2}{|c|}{ CD at $5 \%$} & 0.11 & 0.56 & \\
\hline \multicolumn{2}{|l|}{ CV } & 3.24 & 3.14 & \\
\hline
\end{tabular}

* represents average of three replication.

Plate.1 In vitro screening of different chilli varieties against Colletotrichum capsici

\begin{tabular}{|c|c|c|}
\hline $\begin{array}{l}\text { Name of } \\
\text { variety }\end{array}$ & Inoculated fruits & Control \\
\hline LUCKNOW-1 & & \\
\hline CHIHYB9 & & \\
\hline CHIHYB11 & & \\
\hline CHIHYB12 & & \\
\hline CHIHYB13 & & \\
\hline
\end{tabular}




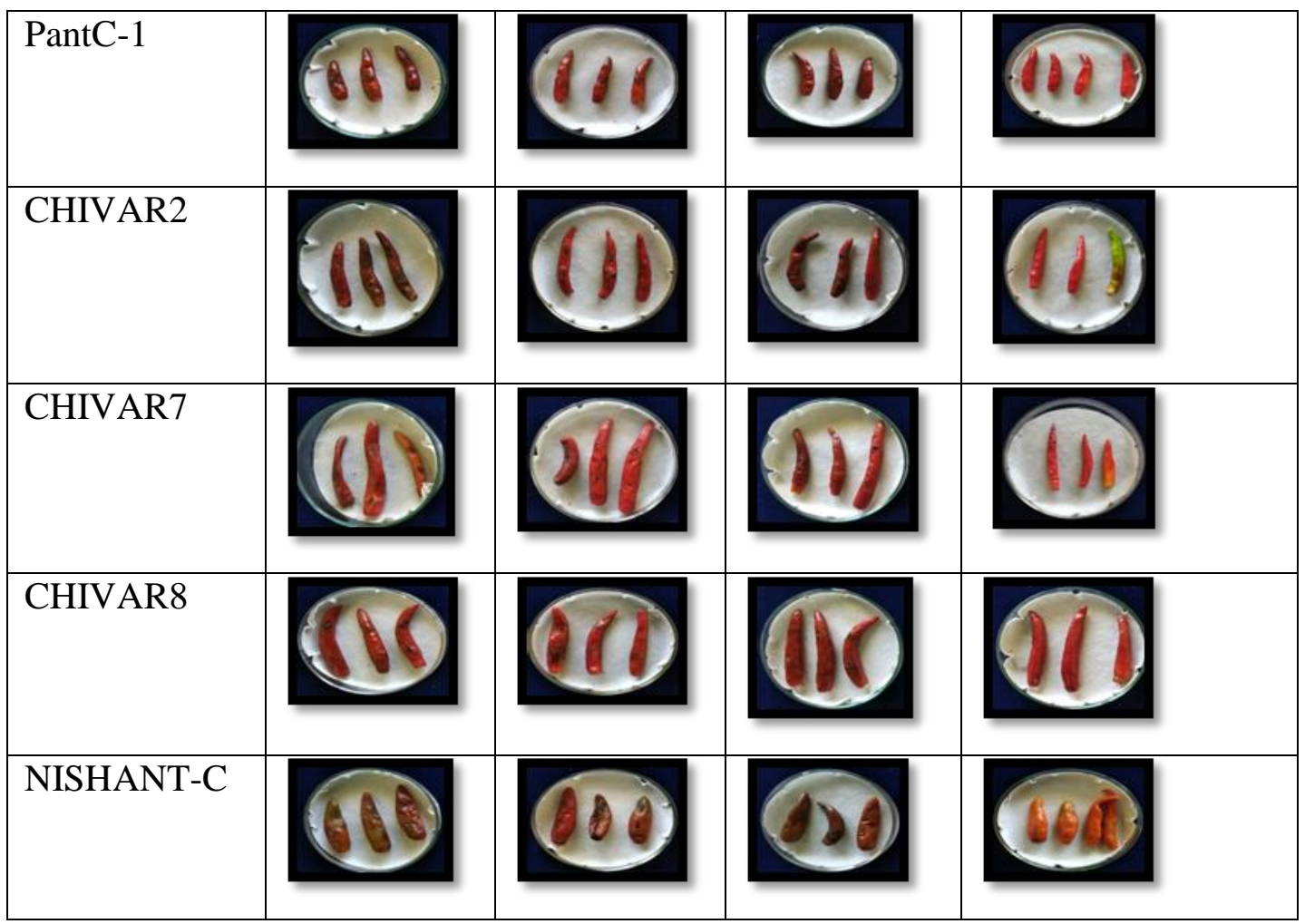

Two varieties CHIVAR -2 and CHIHYB-12 showed susceptible reaction having mean lesion length of 2.13 and $2.61 \mathrm{~cm}$ and PDI of 27.72 and 31.81 respectively. Rest two varieties CHIHYB-9 and NISHANT showed highly susceptible reaction with maximum mean lesion length of 3.80 and $3.95 \mathrm{~cm}$ and PDI of 51.05 and 58.70, respectively. Among the ten varieties, six varieties showed moderately resistant reaction, two susceptible and other two highly susceptible reactions. Among these varieties Pant C-1 was found to be much better with minimum lesion length followed by LUCKNOW-1 and NISHANT was found to be highly susceptible followed by CHIHYB-9 with maximum mean lesion length.

These results are in accordance with the results of Garg et al., (2013) who reported that out of 41 genotypes, 11 varieties are highly resistant and nine genotypes (BS-35, BS-20, BS28, Punjab Lal, Bhut Jolokia, Taiwan-2, IC-383072, Pant C-1 and Lankamura Collection showed consistent resistance reaction after $9 \mathrm{DAI}$ in field and lab condition. Similarly, Gupta et al., (2018) screened 25 varieties and reported that varieties Arka Harita, Classica-152 and Madhurima-148 showed resistance reaction whereas EC-341075, Pusa Jwala, Pant C-1, Arka Meghna, LAC-434 and Sonakshi-44 showed moderately resistance reaction as compared to rest of varieties after five, seven and ten days of inoculation. Mishra et al., (2018) screened 49 chili genotypes against $C$. capsici and found that six genotype viz. Acchar lanka, CA-4, Pant C-1, Punjab Lal, Bhut Jolokia and BS-35 showed resistant response under both field and lab conditions. Pant C-1, the local variety showed susceptible reaction as compared to other varieties tested which showed highly susceptible reaction.

Thus, it can be concluded that there are sources of resistance to anthracnose available in the genotypes accessions which needs to be identified. This depicts the need to screen the genotypes in hotspots for extended period of time to avoid disease escapes and to obtain 
true disease resistant genotypes to develop disease resistant varieties for successful cultivation of chilli.

\section{References}

Anand, T., Chandrasekaran, A., Kuttalam, S., Senthilraja, G., and Samiyappan, R. 2010. Integrated control of fruit rot and powdery mildew of chilli using the biocontrol agent Pseudomonas fluorescens and a chemical fungicide. Biological Control. 52: 1-7.

Anonymous (2018). Directorate of agriculture, Uttarakhand. http://agriculture.uk.gov.in.

Bailey, J. A. and Jeger, M. J. 1992. Colletotrichum: Biology, Pathology and Control. Commonwealth Mycological Institute, Wallingford. 388p.

Dean, R., VanKan, J. A. L., Pretorius, Z. A., Hammond-Kosack, K. E., Di Pietro, A. and Spanu, P. D. 2012. The top ten fungal pathogens in molecular plant pathology. Mol. Plant Pathol. 13: 414 430.

Freeman, S., Katan, T.and Shabi, E.1998. Characterization of Colletotrichum species responsible for anthracnose diseases of various fruits Plant Dis. 82(6): 596-605.

Garg, R., Kumar, S., Kumar, R., Loganathan, M., Saha, S., Kumar, S. and Roy, B. K. 2013. Novel source of resistance and differential reactions on chilli fruit infected by Colletotrichum capsici. Australian Plant Pathology. 42(2): 227233.
Grubben, G.J.H. and Mohamed El. T. I. 2004. "Capsicum annuum L."in PROTA Vegeta Vegetables/ Legumes, eds G.J.H.Grubben and O.A. Denton (Wageningen: PROTA), pp.154-163.

Gupta, V., Kaur, A., Singh, A., Shekhar, H., Singh, R. and Bobde, A. 2018. Screening of different chilli genotypes against anthracnose disease (C. capsici) under controlled condition. Int.J.Curr.Microbiol.App.Sci. $\quad 7(3)$ 2328-2334.

Isaac, S. 1992. Fungal Plant Interaction. : Chapman and Hall Press, London. $115 \mathrm{p}$.

Jeyalakshmi, C. and Seetharaman, K. 1998. Evaluation of chilli genotypes agains fruit rot disease incited by Colletotrichum capsici (syd.) Butler and Bisby. South Indian Horticulture. 46: 104-105.

Mishra, R., Rout, E. and Joshi, R. K. 2018. Identification of Resistant Sources Against Anthracnose Disease Caused by Colletotrichum truncatum and Colletotrichum gloeosporioides in Capsicum annuum L. Proceedings of the National Academy of Sciences, India Section B: Biological Sciences. pp. 1-8.

National Horticulture Board-2017-18 (http://nhb.gov.in/statistics/State_Level/ 2017-18).

Singh, R. S., Singh, P. N. and Singh, D. R. 1993. Note on fruit rot disease of chilli. Indian Journal of Agricultural Research.11: 188-190.

\section{How to cite this article:}

Manoj Kumar Prajapati, Dr. Shilpi Rawat, Deepak Prakash, Kripa Shankar and Jitesh Kumar. 2020. In vitro Screening of Chilli (Capsicum anum L.) Genotypes against the Colletotrichum capsici causing Anthracnose of Chilli. Int.J.Curr.Microbiol.App.Sci. 9(07): 1313-1318. doi: https://doi.org/10.20546/ijcmas.2020.907.151 